\title{
As artes performativas e os desafios do futuro
}

https://doi.org/10.21814/uminho.ed.25.10

\section{Francesca Rayner}

Francesca Rayner (ORCID: 0000-0003-3601-815X) é Professora Auxiliar no Instituto de Letras e Ciências Humanas da Universidade do Minho, onde leciona unidades curriculares de graduação e pós-graduação em Teatro e Performance. É investigadora do CEHUM desenvolvendo pesquisas sobre a política cultural da performance, com um ênfase em Shakespeare no contexto português e nas questóes de género e de sexualidade. Está neste momento a preparar um livro com o título "Shakespeare and the Challenge of the Contemporary" para a editora Arden Bloomsbury. 


\section{CONFINAMENTO, CONTÁGIO E COMUNIDADE}

À medida que os artistas voltam lentamente a poder mostrar o seu trabalho ao vivo, vale a pena reflectir em como as artes performativas reagiram à pandemia da COVID-19 e como isso pode ajudar-nos a pensar num futuro desconfinado. Também é importante considerar as mudanças em curso nas próprias artes performativas, à medida que se concebem e imaginam novas formas artísticas e modos de trabalhar no futuro.

Os profissionais das artes performativas não são alheios a emergências sanitárias e a metáforas de contágio. Quando os teatros fecharam portas por causa da peste, Shakespeare e a sua companhia saíram de Londres e andaram em digressão pelas províncias e pelo continente, adaptando as peças a diferentes públicos e lugares. O dramaturgo e teórico francês Antonin Artaud, no ensaio "Teatro e a Peste” (1933), queria que o teatro fosse como a peste, arrasando com as convençốes fatais do teatro do texto, de modo a criar um ritual comunitário de sons e imagens que despertasse as emoçốes e a imaginação do público. Por sua vez, os performers contemporâneos Teatro Praga combinam teatro e peste no próprio nome para ilustrar a sua relação de amor-ódio com o teatro. Pedro Penim, membro deste colectivo, afirma que, na obra da companhia, "há uma crítica e um questionamento permanente em relação à tua herança, ao teu meio, e aos teus pares, mas também há uma vontade de reconhecimento desse meio, onde queremos continuar a trabalhar, nesse território desconfortável” (apud Vicente 2012, p. 74). Este "território desconfortável” onde podem coexistir amor e ódio, tradição e inovação, crítica e cumplicidade, permitiu aos artistas reagir, de maneiras complexas e criativas, à pandemia de hoje.

Os performers também exploraram ideias de confinamento. Por exemplo, em Five Day Locker Piece (1971), Chris Burden fechou-se durante cinco dias num cacifo da Universidade da Califórnia. Coco Fusco e Guilherme Gomez Peña encerraram-se numa gaiola e questionaram o olhar colonial implícito na exposição de sujeitos colonizados, em Two Undiscovered Amerindians Visit (1992-1993). O artista brasileiro Maikon K permaneceu imóvel durante três horas, enquanto uma substância parecida com uma segunda pele secava no próprio corpo, em DNA de Dan (2019). Nestas performances, os artistas exploraram as fronteiras físicas do corpo, criaram rituais comunitários de purificação e transfiguração, exploraram as implicações éticas e políticas da 
posição do espectador e desafiaram a comodificação dos artistas pelas instituiçôes culturais. Porém, estas performances de confinamento foram livremente assumidas como formas de exploração artística. Em contrapartida, o confinamento de hoje foi-lhes imposto. Obrigou-os a apresentar o trabalho online ou a esperar que o desconfinamento (uma das muitas palavras novas que nasceram neste período) reabrisse os teatros e outros espaços de representação. Assim, muitos artistas que já estavam em situação precária têm lutado para sobreviver. Segundo um inquérito do CENA-STE (Sindicato dos Trabalhadores de Espectáculos, do Audiovisual e dos Músicos), 98\% dos profissionais das artes tiveram trabalhos cancelados por causa da pandemia e não é claro que espectáculos vão ser reprogramados e/ou pagos. Lembremos que a crise não afectou apenas quem aparece em palco, mas também os responsáveis por luz e som, relações públicas, programação, bilheteira, uma rede inteira de profissionais. A recente Vigília Cultura e Artes e a iniciativa no Facebook impulsionada pela Acção Cooperativista de Apoio - Artistas, Técnicos e Produtores das fotos em branco com “\# Unidos pelo presente e futuro da Cultura em Portugal” são exemplos da mobilização das/dos artistas para exigir outras condições de trabalho e criação e maior valorização da actividade cultural. Numa iniciativa paralela de solidariedade, David Marques estabeleceu uma rede informal de profissionais das artes performativas na qual quem tinha mais recursos financeiros apoiava quem tinha menos, ou quem não tinha, com alimentos e dinheiro durante os meses de confinamento. Houve ajuda do Ministério da Cultura, mas era inevitável que não chegasse para gerir uma crise prolongada das artes, que esta pandemia só agudizou¹. As redes de apoio e solidariedade foram sempre mecanismos importantes de sobrevivência das artes performativas e, durante a pandemia, constituíram o tipo de "comunidades

\footnotetext{
1 A linha de apoio de emergência ao Sector das Artes teve uma dotação de um milhão de euros, reforçada depois com 700 mil euros. Recebeu 1025 candidaturas. Dos 636 projectos considerados elegíveis, foram apoiados 311 . Sendo um concurso de apoio à criação e não um apoio de emergência sem retorno, implica também a criação dos espectáculos previstos, mas com menos dinheiro. Neste momento existem negociações entre o Governo e profissionais do espectáculo. Em declarações ao Público, Sofia Leal, do CENA-STE, espera que destas reuniôes possa resultar "a elaboração de um quadro legal específico, totalmente diverso do actual, para os trabalhadores e estruturas", assumindo que "este sector, tal como todos os outros, deve ser expurgado de más práticas laborais e vínculos ilegais de contratação” (Público-Ípsilon, 22 de Maio de 2020, 5).
} 
de cuidado" que Judith Butler (2020) indica terem sido o grande traço desta pandemia ${ }^{2}$. Contudo, como resposta mais estruturada à natureza precária do trabalho nas artes performativas, essas iniciativas só podem mitigar as dificuldades do sector e não resolvê-las.

\section{DO PRESENCIAL AO DIGITAL}

No movimento da performance para o digital que ocorreu durante a pandemia, o cenário foi contraditório. Por um lado, mais pessoas ao nível global assistiram a estes espectáculos, e tiveram divulgação mais ampla espectáculos dantes indisponíveis ou de difícil acesso. Estudos no Reino Unido indicam ter havido mais pessoas a ver teatro durante este período, ainda que em Portugal pareça ter acontecido o oposto. Para os jovens artistas, a entrada no digital permite-lhes chegar a públicos difíceis de almejar nas apresentações, nas salas de espectáculo, de uma ou duas noites. Além disso, no digital emergem novos formatos. A companha britânica Forced Entertainment criou três episódios de uma performance intitulada End Meeting for All, paródia aos problemas de ligação, às interrupções e à desajeitada performatividade das reuniões via Zoom, ao passo que jovens artistas sul-africanos criaram a instavela Lockdown Heights. Com o telemóvel, os actores filmaram em casa parcelas individuais, que editaram em episódios de telenovela com dez minutos. Mas a performance ao vivo sem públicos tem implicações ao nível do que Erika Fischer-Lichte (2019) nomeou o "circuito retroactivo auto-referencial”, isto é, a energia do público que influencia os performers no seu desinteresse ou arrebatamento, tal como os performers também influenciam o público levando-o às lágrimas, ao riso ou à mudança de opinião. Ora, no novo contexto, este circuito energético desaparece. Os espectadores não conseguem influenciar as performances, as quais se aproximam, de maneiras diferentes, mais do cinema do que da experiência viva e imprevisível do teatro. Quando as salas reabrirem, com os espectadores separados entre si, pode tornar-se uma experiência desoladora para performers e público e, em vez de dispersar, pode reforçar sentimentos de isolamento social. Mais

\footnotetext{
2 Butler afirma que, "[e]nquanto alguns sustentam que as desigualdades se intensificarão sob as condiçóes da pandemia e o que se seguirá dela, outros sustentam que as comunidades de cuidado que estão se organizando agora irão despertar, ou darão novos contornos potenciais ao socialismo, à solidariedade horizontal e a uma genuína ética do cuidado”.
} 
ainda, a maioria dos espetáculos apresentados online são do passado, enquanto os novos projetos foram cancelados. Como tal, quando regressar a actividade dos teatros, os programadores terão de decidir se apresentam as obras que foram sendo acumuladas nos últimos meses, e que por isso podem encontrar menos eco nos públicos pós-pandemia. Só mais tarde poderão ser vistos os espetáculos em criação neste momento, alguns dos quais poderão vir a abordar diretamente as experiências da pandemia que as pessoas querem ver reflectidas em palco. Esta situação está longe de ser inédita. Após a Revolução de Abril, um grande acumulado de obras censuradas competiu com dramaturgias contemporâneas, e com a representação continuada de dramaturgos do cânone, como Shakespeare e Molière. De igual modo, na perspicaz observação de Jorge de Sena (apud Porto, 1997), os teatros independentes dos finais dos anos 50 e dos anos 60 enfrentaram o mesmo dilema:

Um teatro profissional de ensaio tem, no nosso país, de fazer tudo: representar clássicos que nunca ninguém viu ou ouviu, apresentar como grandes novidades da última hora o que o melhor teatro universal tem produzido com um adiantamento de cinquenta anos, [...] Ora é muito difícil ao mesmo tempo criar-se um estilo onde não há, nem tradições dele [...] ao mesmo tempo saltando de Shakespeare para Guilherme de Figueiredo, de Bernardo Santareno para Eugene O’Neill, do antigo para o moderno, do nacional para o internacional, do literário para o cénico, e vice-versa, conseguir-se que aquele estilo não seja um amável denominador comum, uma arte consumada de fazer depressa e bem.

Em breve, quando os teatros retomarem a actividade, pode haver problemas semelhantes. Manterão o compromisso com quem devia ter apresentado trabalho durante o período de confinamento e reprogramar essas actividades, ou ajudarão a desenvolver novas dramaturgias que reflectem a vivência da pandemia? Num contexto tão competitivo, haverá espaço para a dramaturgia internacional, seja ela canónica ou contemporânea? O mais provável é pedir aos teatros que façam mais com menos, ou seja, tudo isso, mas com menos dinheiro. Mas, há ainda outros factores a considerar. O que vai acontecer aos teatros na reabertura depende do apoio continuado dos públicos e de investimentos avultados na cultura, não só por causa do dinheiro que a cultura gera na 
economia (os números de 2018 indiciam chegar aos 6,3 mil milhóes), mas sobretudo por se tratar de uma componente vital de uma sociedade democrática.

\section{MÁSCARAS E PERFORMATIVIDADE OBRIGATÓRIA}

O teatro mantém uma relação antiga com as máscaras. As máscaras teatrais têm sido usadas para estabelecer um elo humano com forças divinas e, enquanto colectivo, para comentar os acontecimentos da polis. Além disso, têm criado personagens reconhecíveis, como as figuras de Arlequino ou Pantalone na commedia dell'arte. Mais recentemente, a formação teatral de Jacques Lecoq com a 'máscara neutra', pretende tornar os performers mais conscientes dos movimentos involuntários do corpo, muitas vezes esquecidos dada a concentração excessiva no rosto, e em particular nos olhos. Hoje, o que é mais comum e relevante nas máscaras é, obviamente, o medo e a obrigação associados ao seu uso e as relaçốes complexas que se estabelecem com os outros. No início da pandemia, as máscaras eram relativamente homogéneas, distinguindo-se apenas entre as cirúrgicas e as que ficaram conhecidas como comunitárias. Mais recentemente, sobretudo desde o desconfinamento, têm surgido máscaras mais personalizadas, em cor, tamanho, características e padróes, pois as pessoas procuram distinguir-se naquilo que se tornou uma moda imposta e ao nível global. A máscara comunitária indica, assim, uma espécie de performatividade global no seio do quotidiano. A ideia de teatralidade da vida quotidiana foi explorada exaustivamente nos estudos da performance, com os seus empréstimos transdisciplinares das áreas da antropologia, sociologia, linguística, feminismo e teoria queer e pós-colonial. Obras de estudos da performance publicadas no dealbar do milénio, como Perform or Else: From Discipline to Performance (2001), de Jon McKenzie, enfatizaram a natureza obrigatória dessa performatividade, associando assim a performatividade artística às relaçóes laborais, a questóes de imagem corporal e a noçôes tecnológicas de eficiência. Estas obras exploraram ainda o que acontece a pessoas que não performam correctamente e, por isso, se sujeitam a prisão, multas e sançôes sociais. Por um lado, a performatividade generalizada do uso contemporâneo da máscara pode reforçar o anonimato onde medram os regimes autoritários. Por outro, também pode levar a uma noção mais lata de solidariedade democrática. Todos estamos em risco de ficar doentes e morrer, seja um banqueiro, seja uma mulher que 
ganha o salário mínimo (ainda que os mais desfavorecidos tendam a estar mais expostos durante a pandemia). A máscara lembra, pois, que pouco importa o que acumulamos: não somos capazes de fugir à doença e à morte. Como Hamlet apreende nos seus confrontos com a morte, sejamos nós um mendigo, um performer como Yorick, o bobo da corte, ou um poderoso dirigente como Alexandre, o Grande, somos todos alimento para vermes ${ }^{3}$. Logo, a máscara contemporânea apresenta uma ambivalência sociopolítica. Tornar-se-á ela uma prótese que, à semelhança de novas tecnologias de vigilância, marca uma sujeição cada vez maior da população, ou, em contrapartida, evoca a nossa fragilidade e vulnerabilidade e nos faz tratar a nós, aos outros e ao planeta com maior cuidado? Butler defende a persistência dos dois cenários, e, por isso, o conflito entre as duas visões tornar-se-á mais pronunciado. Se tiver razão, as divisões sociais vão extremar-se no futuro próximo. Mas as máscaras comunitárias, ao contrário das teatrais, não tapam os olhos, pelo que potencialmente poderão promover uma maior empatia com o outro.

\section{PENSAR O PRESENTE E O FUTURO}

As artes performativas podem ajudar-nos a reflectir nas dimensóes mais visíveis da pandemia, das máscaras ao confinamento, mas também evocar uma dimensão mais profunda do presente para trazer à tona a sua complexidade, contradiçóes e problemas. Ainda que, em muitos casos, estes problemas nos afectem de maneira semelhante enquanto cidadãos, a abordagem das artes performativas apresenta traços particulares que vale a pena aqui analisar.

Para começar, as artes performativas podem ajudar-nos a explorar o que pensamos e sentimos durante este período e dar-nos um espaço alternativo e mais seguro para debates tantas vezes difíceis e fracturantes. Regressando ao passado, não tão distante, de 2010, tomemos como exemplo The Artist is Present, de Marina Abramović. Nesta performance, Abramović passou oito horas por dia, durante três meses, no MOMA de

\footnotetext{
3 Hamlet afirma, em 4.3: "Em questóes de comida, o verme é o único imperador. Nós engordamos todas as outras criaturas para nos engordarem; e engordamo-nos a nós próprios para engordar as minhocas. Um rei gordo e um pedinte magro nada são senão iguarias variadas: dois pratos, mas para um só mesa - eis a conclusão.”
} 
Nova Iorque, sentada à mesa, em silêncio. As pessoas sentavam-se à vez na cadeira em frente e olhavam para ela. Este enquadramento artístico aparentemente simples tinha efeitos incrivelmente poderosos; muitos dos mais de mil estranhos que se sentaram em frente de Abramović sentiram emoções fortes, que por vezes os levavam às lágrimas. Formaram-se longas filas à porta do museu, as pessoas tinham vontade de participar. $\mathrm{O}$ problema central desta obra é, evidentemente, porque é que as pessoas sentiam que só conseguiam expressar estas emoções com alguém que pessoalmente lhes era estranha e, simultaneamente, uma artista reconhecida? Porém, a performance captava esta dificuldade crescente de as pessoas expressarem emoçôes directamente e realça a importância ética daquilo a que Emanuel Lévinas (2012) chamou o encontro face a face com o outro que pode eliminar a máscara social para revelar essas emoções tácitas. As actuais medidas de distanciamento social poderiam implicar, se a performance se repetisse hoje, o aumento da distância entre artista e público. Mas, como demonstra, é possível criar situações performativas relativamente simples que ajudem afetivamente as pessoas para quem o confinamento foi, mental e fisicamente, perturbador e desconcertante. A performance pode actuar na expressão dessas emoçôes confusas e inquietantes, num ambiente seguro e neutro. A performance também centra a nossa atenção na necessária co-presença dos outros, em particular no facto de haver em nós partes de que só temos consciência no momento de interacção e partilha com os outros. Esta é uma área em que os performers se envolvem intimamente quase todos os dias, pois a maior parte dos processos criativos é, pela sua própria natureza, colaborativa. Trabalhar com os outros pode ser frustrante, enfadonho, desagradável, mas também entusiasmante, surpreendente e comovente. É igualmente motor de transformação, pois as ideias e preconceitos recebidos confrontam a realidade física de todas as pessoas a quem nos referíamos como 'outros' e muda-nos a 'nós' e a 'elas' nesse processo.

Durante o período de pandemia e distanciamento social, muita gente sentiu a fragilidade da vida e do corpo, sobretudo do corpo envelhecido. A obra do encenador Romeu Castellucci expõe esta fragilidade corporal de maneiras que amiúde provocaram o choque do público. Por exemplo, Giulio Cesare (1997) contava com um César mais velho, debilitado, enrugado e nu e um Marco António cuja ausência de cordas vocais fazia parecer cada palavra, pronunciada com uma caixa de voz, exigir um esforço 
sobre-humano. Em On the Concept of the Face, regarding the Son of God (2011), um jovem limpa o rabo e muda a fralda, uma e outra vez, de um pai incontinente num apartamento imaculadamente branco. A situação tornava-se mais vívida com o cheiro das fraldas sujas que emanava do palco para o nariz do público. $\mathrm{O}$ apelo à religião é aqui ambíguo. Por um lado, parecia dar um certo conforto. Por outro, era incapaz de acabar com o sofrimento de pai e filho. Restava a fragilidade do corpo envelhecido e os cuidados físicos continuados do pai pelo filho, que mostram como estas performances podem escorar a nossa reflexão sobre o presente e o futuro através da crua materialidade do corpo, em vez de o situar no mundo abstracto das tecnologias de informação e comunicação. Estas performances foram controversas, mas o que é relevante nesta e na de Abramović é utilizarem metodologias exploratórias sem tentar dar respostas certas ou gerais, serem interrogativas em vez de afirmativas. Defendo que estas qualidades estão particularmente presentes nas artes performativas, e serão vitais para pensar o futuro.

As artes performativas podem somar complexidade emocional e intelectual aos debates em torno da pandemia. Por exemplo, a peça Lava (2018), de James Fritz, abordava os efeitos da colisão de um asteróide em Londres. Por um lado, Jamie, que perdera o pai no acidente, não consegue parar de falar do que aconteceu, o que acaba por esgotar a compaixão de quem o rodeia. Em contrapartida, Vin deixa de comunicar, a não ser nas mensagens de texto à amiga Rach. As reacçóes à tragédia diferem de pessoa para pessoa. Quando Rach descobre que, na verdade, o pai de Vin não morreu e Vin lhe mentiu, ela confronta-o e recusa voltar a falar-lhe. Acaba por perdoá-lo e decide ingressar na política local para ajudar a reconstruir a sua comunidade. A peça sublinha a diversidade de reacçóes pessoais à tragédia, à dor e ao luto sem julgar se são as correctas ou apropriadas. Reconhece que às vezes as pessoas portam-se bem, outras portam-se menos bem. As recomendações oficiais à população durante a pandemia têm, inevitavelmente, de simplificar e exigir a generalização de alguns gestos, como a lavagem das mãos e o uso de máscara. Nestas situações, as artes performativas são um espaço onde explorar, sem julgar, reacções individuais e mais complexas às crises.

Oil (2016), de Ella Hickson, é mais um exemplo. Nela se traça a relação da sociedade ocidental com o petróleo, desde o uso de querosene no século XIX a um futuro, em 2050, em que o petróleo se esgotou. Hickson esquiva-se do que designa 
por “peça do urso polar” sobre o fim desses recursos finitos, mas revela como as sucessivas invençóes de querosene, gasolina e Toraid (uma nova forma de energia inventada por ela, com recurso à fusão a frio gerada por um monopólio chinês na Lua, em 2050) têm sido consideradas, por alguns, símbolos de uma distopia iminente, e por outras oportunidades fascinantes do futuro. Paralelamente a este épico da geopolítica do petróleo, Hickson imagina a história pessoal de mãe e filha; questiona assim as consequências das decisões quando estas têm implicações claras para gerações futuras, mas também como as gerações presentes poderão, em retrospectiva, olhar para algumas decisóes tomadas no passado e questionar as suas premissas políticas, éticas e ambientais. Ao comentar o processo de escrita da peça, Hickson sugeriu que a sua visão distópica do futuro chegou mais depressa do que anteviu, pelo que muitas das previsóes para 2050 já se realizaram em algumas sociedades ocidentais em 2020 . Ao ler esta última parte da peça no contexto da pandemia, parecia mesmo uma visão assustadoramente próxima, e não de um futuro distante.

As artes performativas pressentem muitas vezes os futuros possíveis encerrados no presente, elementos do futuro que ainda só começam a emergir no presente. Surpreende, por exemplo, o número de peças distópicas escritas em 2016 que pareciam antecipar a atmosfera de medo e trauma da actual pandemia. Claro que não foi coincidência 2016 ter sido o ano das eleições norte-americanas que elegeram Trump, mas a leitura de peças como Human Animals, de Stef Smith, não deixa de ser desconfortável nos dias de hoje. A obra aborda uma misteriosa infecção cujo contágio começa por ser identificado em pombos e raposas. Quando se alastra, e mesmo após a morte em massa destas aves e mamíferos menos amados, a mortandade depressa se espalha aos animais domésticos e depois a golfinhos, seguidos de pinguins e, inevitavelmente, dos seres humanos. Smith ilustra a diversidade das reacçóes ao alastramento deste contágio e ao medo que o acompanha, de quem protestam contra a destruição massiva de seres vivos ocultando animais em casa às pessoas cujo maior desejo é estabelecer uma certa dose de normalidade num mundo inexoravelmente transformado. Nas palavras de Smith: "As pessoas conseguem habituar-se a coisas terríveis e muito depressa. Se for preciso. Não é preciso muito para tudo desabar.” Quando lhe perguntaram, recentemente, como conseguira captar este clima de medo do contágio dois 
anos antes da actual pandemia, Smith disse ter recorrido à sua memória da Escócia rural, durante a epidemia de febre aftosa, em 2001, quando um gigantesco número de animais mortos foram incinerados em grandes pilhas, para impedir que a doença se propagasse e quando a comunidade agrícola era obrigada a usar equipamento protector. É um alerta importante de que esta não é, de todo, a primeira epidemia de grande escala e, as ecodramaturgias, como a de Smith, sugerem que não se aprende com as lições do passado, nesta pressa de voltar ao futuro 'normal'.

\section{PARALELOS SHAKESPEARIANOS}

Ocorre-nos inevitavelmente, em crises destas, procurar no passado, e especificamente nas peças de Shakespeare, paralelos com os acontecimentos e as figuras públicas de hoje. Durante a pandemia, traçaram-se várias comparações entre o presidente dos Estados Unidos e, por exemplo, Ricardo III, dado muitos dos seus anteriores aliados terem sido afastados de posiçôes de poder para consolidarem o poder do próprio presidente. Nesta peça, o Escrivão faz um comentário triste sobre a tendência do poder para silenciar a oposição:

Quem será tão lerdo

Que não veja esta trama evidente?

Mas quem ousará não dizer que a não vê?

Mau é o mundo, o pior sempre vai estar

Se tais maldades se não podem nomear (3.6. 10-14).

\footnotetext{
4 A figura do Escrivão, que dá voz às verdades incómodas, poderia ser substituída hoje pela comunidade científica e médica, cujos alertas e recomendaçôes são consistentemente ignorados. Cita-se a tradução por Rui Carvalho Homem (2015). Quando Trump foi fotografado recentemente com uma Bíblia na mão, reforçou-se o paralelo com a cena de subida ao poder de Ricardo III quando aparece ao público no meio de dois bispos (3.7).
} 
Jair Bolsonaro, na tendência para imitar Donald Trump e na linguagem robusta, poderia dar por si a protagonizar uma recente adaptação da peça, com o título menos nobre de Little Dick. Outras referências shakespearianas para a pandemia poderiam ser o final trágico de Rei Lear, quando Edgar conclui "[ $\mathrm{t}$ ]emos de suportar o fardo destes tristes tempos, dizer o que sentimos, não o que devíamos dizer. Os velhos foram quem mais sofreu; nós, que somos jovens, nunca veremos tantas coisas, nem viveremos tanto tempo". Particularmente perturbador neste final é não sentirmos que o futuro pode ser melhor para os mais jovens com o desaparecimento dos mais velhos, observação que, infelizmente, ecoa o que se pensa hoje sobre as perspectivas económicas das gerações futuras e das suas condições de saúde.

O contexto português parece-se mais, felizmente, com uma comédia de Shakespeare, em particular Noite de Reis, filtrada pela melancolia. O primeiro-ministro e o presidente seriam a dupla cómica do ebuliente D. Telmo Sandeman e do raquítico D. André Carabanda ${ }^{5}$. A ministra da Cultura seria Maria, ama e mediadora entre Festa, o bobo e os que o querem expulsar de casa. O ministro das Finanças seria Malvolio, mantendo o lar controlado de uma maneira que, inevitavelmente, acaba por antagonizar os outros. Festa - o bobo que se move entre dois universos domésticos, vive do engenho e se arrisca sempre a ficar lá fora, à chuva e ao vento - seria a precária classe artística. Porém, para a maioria da população portuguesa, talvez seja Violeta quem dá voz à opinião comum do momento que vivemos. Perante escolhas impossíveis, conclui ela: "Só o tempo poderá desenvencilhar isto, que nem eu/Este novelo pôs-se demasiado embrulhado para mim" (2.2). A fé dela de que o tempo há-de acabar por resolver a situação está longe de ser fatalista. Ela continua a agir e a dizer o que pensa. Contudo,

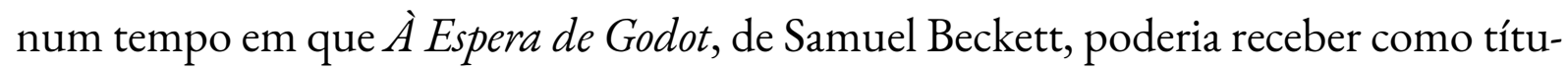
lo, para o público contemporâneo, À Espera de Uma Vacina, e com demasiadas teorias sobre o futuro, o que se compreende, o simples reconhecimento por Violeta de que há tanta coisa sobre o vírus e o futuro que pura e simplesmente desconhecemos e que não controlamos deixa-nos à vontade para nos preocuparmos mais com o presente, en-

5 Cita-se a tradução destes nomes por António M. Feijó na sua tradução para o Teatro Nacional São João, em 1998, numa performance encenada por Ricardo Pais. 
quanto antídoto para olharmos com nostalgia para o passado ou pensarmos demasiado num futuro incerto.

Como ilustrado pelo exemplo shakespeariano, reduzir a dimensão de figuras poderosas ou hipócritas por via do humor tem sido constante nas artes performativas, do Tartufo (1664), de Molière, a Ubu Roi (1896), de Alfred Jarry, e geralmente associa-se certo humor negro aos profissionais de saúde e a quem lida diariamente com a doença e a morte. O humor também aponta para os caminhos a que as artes performativas se têm associado, não só pela seriedade do ritual, mas também pela liberdade lúdica e os momentos em que os participantes se podem esquecer de si; no movimento profundo de deep play, são contrapesos necessários à seriedade de uma pandemia.

\section{FUTUROS PROVÁVEIS E POSSÍVEIS}

As artes performativas exploram os futuros prováveis, mas também os possíveis. Contra um regresso à 'normalidade' que inclui muitos elementos que não quereríamos transportar connosco para o futuro, e a construção de uma 'nova normalidade' que se limita a reforçar a vigilância e o autoritarismo de um presente distópico, as artes performativas podem ser um laboratório de experimentação que, através do no método de tentativa e erro, explora alternativas aos mecanismos globais envolvidos que trouxeram a nesta pandemia e que ameaçam o nosso futuro. Com uma sociedade potencialmente mais fracturada, as performances que permitem aprofundar e debater dilemas sociais desempenham um papel relevante. Por exemplo, a premissa de Atlas (2012), de João Galante e Ana Borralho, é simples. Os artistas convidaram cem pessoas a participar numa performance para a qual se limitavam a dizer como ganhavam a vida. À vez, cada pessoa avançava no palco e dizia uma variante da mesma frase: "Se um [cabelereiro/ pastor/técnico de contas] incomoda muita gente, [dois/três cabelereiros/pastores/técnicos de contas] incomodam muito mais." A segunda parte era dita em coro por todos os presentes em palco. O orgulho e a paixão com que as pessoas falavam da sua profissão era palpável, e os performers acrescentaram pequenos pormenores à frase, de que é exemplo a mulher cuja "profissão" era ser doméstica e se orgulhava de os filhos terem as vacinas em dia. Quando, no auge das medidas de austeridade, a 40a pessoa subiu ao palco e disse: "Se quarenta desempregados incomodam muita gente", e as outras 39 com- 
pletaram em coro: "555000 incomodam muito mais", o teatro irrompeu em aplausos espontâneos, de um público muito mais diverso que o habitual, pois a comunidade local fora ver os seus familiares e amigos neste espetáculo. Apesar das graves dificuldades, muitos dos que regressam hoje ao trabalho, ou que trabalharam durante o confinamento, fizeram-no com um sentido de missão renovado. Quem perdeu o emprego pode sentir igual necessidade de dar testemunho público das dificuldades em lidar com esta situação, e de igual validação colectiva do seu valor e mérito. Atlas tocou no âmago de um problema nas bocas de toda a gente - o desemprego crescente - e imaginou um futuro alternativo comum fundado não numa avaliação económica, mas num sentido de mérito e propósito, seja por via do trabalho, seja por via de uma relação solidária com os outros, seja por via da ideia lúdica e séria de fazer teatro. Os corpos e as vozes do desempregado, do marginal e do diferente raramente aparecem na esfera pública, e o teatro permite ver estes corpos e ouvir estas vozes.

E quanto ao futuro da própria universidade? Presa entre o autoritarismo crescente, de um lado, e a instabilidade social e os apelos à mudança, por outro, dará por si numa posição difícil. Forçada a competir num mercado global em que o ensino online vai alargar, do ponto de vista geográfico, as oportunidades de encontrar alunos, bem como a reforçar as suas relaçôes com as comunidades locais, as pressóes podem conduzir a universidade em sentidos contrários.

O performer Rogério Nuno Costa encontra-se a concluir um mestrado na Universidade das Artes de Helsínquia, na Finlândia, no qual explora a performatividade das práticas universitárias, ou seja, os rituais tão aceites na academia e, por isso, raramente questionados. Em vez de assumir, por exemplo, que a primeira tarefa de um colóquio é convidar um orador, Rogério Nuno Costa formula antes esta pergunta: de que falamos nós quando falamos de um colóquio? A sua pesquisa levou a muitas discussões e debates interessantes no Grupo de Investigação em Artes Performativas da Universidade do Minho, e no projecto final de mestrado, que combina texto e performance, propóe que a 'universidade' se torne uma 'multiversidade'. Como se tornou bem evidente neste período de ensino online, há grandes diferenças entre alunos universitários, quer financeiras e tecnológicas, quer ao nível da saúde física e mental. Essa diversidade, aliada à diversidade de género, sexo, raça e idade destes alunos, está no 
centro da multiversidade, que também valoriza a diversidade de perspectivas e perfis de alunos, professores, administradores e pessoal administrativo. Na esteira da ideia de multiversidade, Rogério Nuno Costa aceitou que se comente e acrescente à proposta via Google Docs, evitando as hierarquias e separaçôes entre artistas e académicos, entre quem tem mais autoridade e quem tem menos. Este projecto teórico e prático parece-me ser um valioso contributo para, do ângulo das artes performativas, reflectir sobre o futuro da universidade. Em vez de implementar o que se sabe e está estabelecido, procura investigar e experimentar. Esforça-se por promover a diversidade em lugar da homogeneidade, e tem múltiplos pontos de entrada numa estrutura rizomática em vez de uma estrutura hierárquica. A universidade, tal como as artes performativas, pode aproveitar esta mudança abrupta nas nossas vidas e rotinas para repensar o seu propósito e situar as questôes da democracia, da diferença e da justiça social no centro das suas práticas, de forma criativa e plural.

\section{REFERÊNCIAS BIBLIOGRÁFICAS}

Artaud, A. (s/d). O teatro e a Peste. O Teatro e o Seu Duplo. São Paulo: Martins Fontes. 9-30.

Butler, J. (2020). Traços Humanos nas Superfícies do Mundo. Trad. André Arias e Clara Barzaghi. Disponível em https://n1edicoes.org/042?fbclid=IwAR2H4Sx0INBbOcETancuii5aTLFsl2u9pAEOZqaAxxFyKBWhY3tsV3MerMo. Consultado em 25.5.2020.

Fischer-Lichte, E. (2019). Estética do Performativo. Trad. Manuela Gomes. Lisboa: Orfeu Negro.

Fritz, J. (2018). Lava. London: Nick Hern Books.

Hickman, E. (2016). Oil. London: Nick Hern Books.

Lévinas E. (2012). O Humanismo do outro Homem. 4a ed. Petrópolis: Vozes.

McKenzie, J. (2001). Perform or Else: From Discipline to Punish. London and New York: Routledge.

Porto, C. (1997). O TEP e o Teatro em Portugal. Porto: Fundação António de Almeida, 260.

Shakespeare, W. (2015). Ricardo III. Trad. Rui Carvalho Homem. Lisboa: Relógio d’Água.

Shakespeare, W. (1998). Noite de Reis, ou como lhe queiram chamar. Trad. António M. Feijó. Lisboa: Cotovia.

Shakespeare, W. (1987). Hamlet. Trad. Sophia de Mello Breyner Andresen. Porto: Lello \& Irmão.

Smith, Stef. (2016). Human Animals. London: Nick Hern Books.

Vicente, G. (2012). Geração sem Fronteiras. Sinais de Cena, 12, 70-78. 